\title{
Energy demands of diverse spiking cells from the neocortex, hippocampus, and thalamus
}

\author{
Abdelmalik Moujahid *, Alicia D’Anjou and Manuel Graña \\ Computational Intelligence Group, Department of Computer Science and Artificial Intelligence, University of the Basque Country UPVIEHU, San Sebastián, Spain
}

\section{Edited by:}

David Hansel, University of Paris,

France

\section{Reviewed by:}

Da-Hui Wang, Beijing Normal

University, China

Emili Balaguer-Ballester,

Bournemouth University, UK

*Correspondence:

Abdelmalik Moujahid,

Computational Intelligence Group, Department of Computer Science and Artificial Intelligence, University of the Basque Country UPVIEHU,

Pa Lardizabal, 1, 20018 San

Sebastián, Guipuzcoa, Spain

e-mail: jibmomoa@gmail.com
It has long been known that neurons in the brain are not physiologically homogeneous. In response to current stimulus, they can fire several distinct patterns of action potentials that are associated with different physiological classes ranging from regular-spiking cells, fast-spiking cells, intrinsically bursting cells, and low-threshold cells. In this work we show that the high degree of variability in firing characteristics of action potentials among these cells is accompanied with a significant variability in the energy demands required to restore the concentration gradients after an action potential. The values of the metabolic energy were calculated for a wide range of cell temperatures and stimulus intensities following two different approaches. The first one is based on the amount of $\mathrm{Na}^{+}$load crossing the membrane during a single action potential, while the second one focuses on the electrochemical energy functions deduced from the dynamics of the computational neuron models. The results show that the thalamocortical relay neuron is the most energy-efficient cell consuming between 7 and $18 \mathrm{~nJ} / \mathrm{cm}^{2}$ for each spike generated, while both the regular and fast spiking cells from somatosensory cortex and the intrinsically-bursting cell from a cat visual cortex are the least energy-efficient, and can consume up to $100 \mathrm{~nJ} / \mathrm{cm}^{2}$ per spike. The lowest values of these energy demands were achieved at higher temperatures and high external stimuli.

Keywords: computational models, action potential, neuron metabolic energy, sodium entry, overlap load

\section{INTRODUCTION}

A huge number of studies have been devoted to categorize neurons in the brain according to various criteria such as morphology, physiology, biochemical properties and synaptic characteristics (Peters et al., 1984; White, 1989; Cauli et al., 1997; Toledo-Rodriguez et al., 2003). However, relatively little has been said about their classification in terms of energy demands. The relationship between the action potentials characteristics and the energy cost required to generate them has been reported recently (Crotty et al., 2006; Carter and Bean, 2009; Sengupta et al., 2010). Nonetheless, as in many other works, the calculations of the metabolic energy involved in the generation of action potentials are based on the ion-counting methods that generally focus on the number of ATP molecules hydrolyzed by the sodium pump.

It is well known that $\mathrm{Na}^{+}$and $\mathrm{K}^{+}$are the most important ions with greater impact on the membrane potential dynamics and on its energetics (Ames III, 2000). In fact, these two ions together with $\mathrm{Ca}^{2+}$ account for the major ions whose movements consume ATP molecules. During the generation of action potentials, the electrochemical gradients are partially altered and must be restored by $\mathrm{Na}^{+} / \mathrm{K}^{+}$pump which mediates influx of $2 \mathrm{~K}^{+}$ in exchange for $3 \mathrm{Na}^{+}$per 1 ATP molecule consumed (Kandel et al., 1991). Estimations of the energy consumed by the neuron during its signaling activity are usually intended by extrapolating from a Hodgkin-Huxley type model the number of sodium ions required to depolarize the membrane in order to know the amount of ATP molecules that will be needed for the pump to reestablish its rest potential. This method, known as ion counting approach, corresponds to the first approach to account with the neuron energy (Laughlin et al, 1998; Attwell and Laughlin, 2001; Alle et al., 2009). Taking into account that action potential propagation following Hodgkin/Huxley kinetics is based on equal $\mathrm{Na}^{+}$efflux and $\mathrm{K}^{+}$influx, this approach could lead to overestimate/underestimate values of energy (Hertz et al., 2013). For one hand, because of the asymmetry between $\mathrm{Na}^{+}, \mathrm{K}^{+}$-ATPase mediated $\mathrm{Na}^{+}$and $\mathrm{K}^{+}$fluxes. And, for the other hand, due to the overlap of inward and outward currents during an action potential generation. In fact, inward $\mathrm{Na}^{+}$and outward $\mathrm{K}^{+}$overlap during the action potential generation introducing an uncertainty in the calculation of sodium ions up to a factor of 4 (Hodgkin, 1975; Attwell and Laughlin, 2001; Lennie, 2003).

Based on computational models that capture the intrinsic properties of action potentials from different mammalian neurons, this work provides a quantitative comparison of the amount of ionic currents crossing the membrane during an action potential and their corresponding energy demands focusing on a new approach. This approach is based on the biophysical considerations about the nature of computational models used to account for neuronal spiking response, and gives an alternative method to deduce the electrochemical energy involved in the dynamics of the neuron model. Unlike the ion counting approach, this method requires no hypothesis about the stoichiometry of the ions or the extent of the overlapping between $\mathrm{Na}^{+}$and $\mathrm{K}^{+}$ions and, most 
importantly, offers the possibility to compute the energy consumption of coupled neurons (Moujahid et al., 2010, 2011), especially when considering complex networks where all the interactions should be considered. As commented in Buzsaki et al. (2007) it is not possible to estimate energetic costs in isolation. As far as possible the complexity of the interactions should be taken into account.

The analytical expression of the electrochemical energy involved in the dynamics of the classical Hodgkin-Huxley model consisting of sodium, potassium and leakage currents has been reported previously in Moujahid et al. (2011, 2012). Here we provide energy functions of different spiking neurons where additional ionic currents are involved. The intrinsic properties of the computational models, considered in this work, arise from voltage-dependent conductances described by Hodgkin-Huxley type kinetics. These models were adjusted in previous studies (Wang and Buzsáki, 1996; Guo et al, 2008; Pospischil et al., 2008) to experimental data from different preparations to reproduce the firing characteristics of different neuron classes present in neocortex, thalamus and hippocampus. These neurons include regular spiking (RS) cells, fast spiking, intrinsically bursting (IB), hippocampal fast-spiking interneuron (HFI) and thalamocortical relay neuron (TCR). The RS and FS models can reproduce respectively firing properties of RS and FS cells as observed both in intracellular recordings of cells in ferret visual cortex and in rat somatosensory cortex. Meanwhile, IB neuron models reproduce the typical firings of intrinsically bursting cells in guinea-pig somatosensory cortex and in cat visual cortex. The other two neuron models capture the typical spiking as seen in rat hippocampal interneuron and a mouse thalamocortical relay neuron, respectively.

The paper is organized as follows. First, we introduce the dynamics and electrochemical energy of the Hodgkin-Huxley like models used to account for the spiking response of different classes of neurons present in neocortex, thalamus and hippocampus. Then we describe the kinetic of these neurons according to the ionic currents involved in their dynamics. Results are reported and discussed in section 3. Finally, section 4 draws conclusions and open questions.

\section{MATERIALS AND METHODS}

\subsection{DYNAMICS OF THE SPIKING NEURON MODELS}

All computational models were modeled using a HodgkinHuxley type of kinetic model (Hodgkin and Huxley, 1952), and run using the Matlab simulation environment. For all these models, the dynamics governing the membrane potential obeys the following equation:

$$
C \dot{V}=-g_{l}\left(V-E_{l}\right)-I_{N a}-I_{K}-I_{M}-I_{L}-I_{T}+I_{S t i m},
$$

where $V$ is the membrane potential in $\mathrm{mV}, g_{l}$ is the maximal conductance per unit area for the leakage channel, and $E_{l}$ is the corresponding reversal potential. $I_{\text {Stim }}$ is the total membrane current density in $\mu \mathrm{A} / \mathrm{cm}^{2}$. $C$ is the membrane capacitance in $\left(\mu \mathrm{F} / \mathrm{cm}^{2}\right) . I_{N a}, I_{K}\left(I_{M}\right)$, and $I_{L}\left(I_{T}\right)$ are the sodium, potassium (slow potassium) and calcium (low-threshold calcium) currents, respectively.

\subsubsection{Neocortical neurons}

In the models used to account for the different firing patterns characterizing cells in the neocortex, $I_{N a}=g_{N a} m^{3} h\left(V-E_{N a}\right)$ and $I_{K}=g_{K} n^{4}\left(V-E_{K}\right)$ are the sodium and potassium currents responsible for action potentials. $I_{M}=g_{M} p\left(V-E_{K}\right)$ is a slow voltage-dependent potassium current responsible for spikefrequency adaptation, and $I_{L}=g_{L} q^{2} r\left(V-E_{C a}\right)$ is a calcium current to generate bursting.

The gating variables $m, h, n, q$ and $r$ obey the standard kinetic equation, $\dot{x}=\alpha_{x}(1-x)-\beta_{x} x$, where $x=m, h, n, q, r$ and $\alpha_{x}$ and $\beta_{x}$ are voltage-dependent variables. $m$ and $h$ are sodium channels activation and deactivation variables, $n$ is potassium channels activation variable, and $q$ and $r$ are calcium activation and inactivation variables. The gating variable $p$ associated with the slow voltage-dependent potassium current is governed by the following equation: $\dot{p}=\left(p_{\infty}(V)-p\right) / \tau_{p}(V)$.

The RS model consists of the sodium and potassium currents responsible for action potentials $\left(I_{\mathrm{Na}}\right.$ and $\left.I_{K}\right)$ and a slow voltagedependent potassium current responsible for spike-frequency adaptation $\left(I_{M}\right)$. The IB model includes the same ionic currents as in the RS ones and an additional L-type calcium current $\left(I_{L}\right)$. The simple FS model accounts only for the currents responsible of spike generation (i.e., $I_{\mathrm{Na}}$ and $I_{K}$ ), and reproduces the spiking properties of FS cells as observed from ferret Visual Cortex in vitro. To capture the firing characteristics of FS cells as recorded from somatosensory cortex in vitro a slow potassium current $\left(I_{M}\right)$ has been added to the simple FS model.

\subsubsection{Thalamocortical relay neuron}

The thalamocortical relay neuron model consists of currents responsible for generating spikes, $I_{N a}=g_{N a} m_{\infty}^{3} h\left(V-E_{N a}\right)$ and $I_{K}=g_{K}(0.75(1-h))^{4}\left(V-E_{K}\right)$, as well as, low-threshold calcium current, $I_{T}=g_{T} p_{\infty}^{2} r\left(V-E_{T}\right)$. The dynamics of the gating variables $h$ and $r$ obey respectively the equations $\dot{h}=\left(h_{\infty}-\right.$ $h) / \tau_{h}$ and $\dot{r}=\left(r_{\infty}-r\right) / \tau_{r}$. This model achieves a single spike activity consisting of trains of action potentials whose frequency depends on the strength of depolarization. When exposed to depolarizing current pulse of constant amplitude it results in a train of action potentials with no frequency adaptation.

\subsubsection{Hippocampal interneuron}

Finally, the hippocampal interneuron model obeys the same current-balance equation (Equation 1), and consists of leak current and the spike-generating $\mathrm{Na}^{+}$and $\mathrm{K}^{+}$voltage-dependent ion current $\left(I_{N a}=g_{N a} m_{\infty}^{3} h\left(V-E_{N a}\right)\right.$ and $\left.I_{K}=g_{K} n^{4}\left(V-E_{K}\right)\right)$. For the transient sodium current, the activation variable $m$ is assumed fast and substituted by its steady-state function $m_{\infty}=\alpha_{m} /\left(\alpha_{m}+\right.$ $\left.\beta_{m}\right)$. This model has the ability to reproduce repetitive spikes at high frequencies in response to a constant injected current. It has a small current threshold (the rheobase $I_{\text {stim }} \simeq 0.25 \mu \mathrm{A} / \mathrm{cm}^{2}$ ), and the firing rate is as high as $400 \mathrm{~Hz}$ for $I_{\text {stim }}=20 \mu \mathrm{A} / \mathrm{cm}^{2}$.

In this work, we use the conductance-based model by Pospischil et al. (2008) to reproduce the main features of the typical firing pattern of RS, FS and IB neurons as observed in different cells in the neocortex. The computational models used to account for the firing characteristics of thalamocortical relay neuron and the hippocampal fast-spiking interneurons follow respectively the 
works by Wang and Buzsáki (1996), Sohal et al. (2002), and Guo et al (2008). The forms of the activation and inactivation functions describing the ion currents of all these models are reported in Table 1. The the values of biophysical parameters characterizing each of these models are shown in Table 2, and give rise to 10 different cells. Cell 1 is a RS cell from ferret visual cortex, Cells 2 and 3 are respectively excitatory and inhibitory RS cells from a rat somatosensory cortex, Cells 4 and 5 are respectively FS cells from ferret visual cortex and rat somatosensory cortex, Cells 6 and 7 are both IB cells from guinea-pig somatosensory cortex (Cell 6 is characterized by an initial burst followed by adaptive action potentials, while Cell 7 gives rise to repetitive bursting.), Cell 8 is an IB cell from a cat visual cortex, Cell 9 is a mouse thalamocortical relay cell, and finally Cell 10 account for a rat hippocampal interneuron.

\subsection{IONIC CHANNELS ENERGY IN SPIKING NEURON MODELS}

The procedure followed to find the electrochemical energy involved in the dynamics of the Hodgkin-Huxley circuit consisting of capacitor $C$ and three $\mathrm{Na}, \mathrm{K}$, and $\mathrm{L}$ ionic channels has been reported in detail in Moujahid et al. (2011). Here we extend this procedure to deduce the energy functions characterizing the dynamics of Hodgkin-Huxley-like models where additional ionic channels are present. For the system given by Equation (1), the total electrical energy accumulated in the circuit at a given moment in time is,

$$
H(t)=\frac{1}{2} C V^{2}+H_{l}+H_{N_{a}}+H_{K}+H_{M}+H_{L}+H_{T},
$$

where the first term in the summation gives the electrical energy accumulated in the capacitor and represents the energy needed to create the membrane potential $V$ of the neuron. The other six terms are the respective energies in the batteries needed to create the concentration jumps in chloride, sodium, potassium and calcium. The electrochemical energy accumulated in the batteries is unknown. Nevertheless, the rate of electrical energy provided to the circuit by a battery is known to be the electrical current through the battery times its electromotive force.

Table 1 | The activation and inactivation functions describing ion currents.

\begin{tabular}{|c|c|c|}
\hline & Activation & Inactivation \\
\hline \multicolumn{3}{|l|}{ NEOCORTICAL CELLS } \\
\hline \multirow[t]{2}{*}{$I_{N a}=g_{N a} m^{3} h\left(V-E_{N a}\right)$} & $\alpha_{m}(V)=\frac{-0.32\left(V-V_{T}-13\right)}{e^{-\left(V-V_{T}-13\right) / 4}-1}$ & $\alpha_{h}(V)=0.128 e^{-\left(V-V_{T}-17\right) / 18}$ \\
\hline & $\beta_{m}(V)=\frac{0.28\left(V-V_{T}-40\right)}{e^{\left(V-V_{T}-40 / 5\right)}-1}$ & $\beta_{h}(V)=\frac{4}{e^{-\left(V-V_{T}-40\right) / 5}+1}$ \\
\hline \multirow[t]{2}{*}{$I_{K}=g_{K} n^{4}\left(V-E_{K}\right)$} & $\alpha_{n}(V)=\frac{-0.032\left(V-V_{T}-15\right)}{e^{-\left(V-V_{T}-15\right) / 5}-1}$ & \\
\hline & $\beta_{n}(V)=0.5 e^{-\left(V-V_{T}-10\right) / 40}$ & \\
\hline$I_{M}=g_{M} p\left(V-E_{K}\right)$ & $p_{\infty}(V)=\frac{1}{e^{-(V+35) / 10}+1}$ & $\tau_{p}(V)=\frac{\tau_{\max }}{3.3 e^{(V+35) / 20}+e^{-(V+35) / 20}}$ \\
\hline \multirow[t]{2}{*}{$I_{L}=g_{L} q^{2} r\left(V-E_{C a}\right)$} & $\alpha_{q}(V)=\frac{0.055(-27-V)}{e^{(-27-V) / 3.8}-1}$ & $\alpha_{r}(V)=0.000457 e^{(-13-V) / 50}$ \\
\hline & $\beta_{q}(V)=0.94 e^{(-75-V) / 17}$ & $\beta_{r}(V)=\frac{0.0065}{e^{(-15-V) / 28}+1}$ \\
\hline \multicolumn{3}{|c|}{ THALAMOCORTICAL RELAY (TCR) CELL } \\
\hline$I_{N a}=g_{N a} m_{\infty}^{3} h\left(V-E_{N a}\right)$ & $m_{\infty}(V)=1 /\left(e^{-(V+37) / 7}+1\right)$ & $h_{\infty}(V)=1 /\left(e^{(V+41) / 4}+1\right)$ \\
\hline \multirow[t]{3}{*}{$I_{K}=g_{K}(0.75(1-h))^{4}\left(V-E_{K}\right)$} & & $\tau_{h}(V)=1 /\left(a_{1}(V)+b_{1}(V)\right)$ \\
\hline & & $a_{1}(V)=0.128 e^{(-(V+46) / 18)}$ \\
\hline & & $b_{1}(V)=4 /\left(1+e^{(-(V+23) / 5)}\right)$ \\
\hline \multirow[t]{2}{*}{$I_{T}=g_{T} p_{\infty}^{2} r\left(V-E_{T}\right)$} & $p_{\infty}(V)=1 /\left(e^{-(V+60) / 6.2}+1\right)$ & $r_{\infty}(V)=1 /\left(e^{(V+84) / 4}+1\right)$ \\
\hline & & $\tau_{r}(V)=0.4\left(e^{-(V+25) / 10.5}+28\right)$ \\
\hline \multicolumn{3}{|c|}{ HIPPOCAMPAL INTERNEURON (RHI) } \\
\hline \multirow[t]{3}{*}{$I_{N a}=g_{N a} m_{\infty}^{3} h\left(V-E_{N a}\right)$} & $m_{\infty}(V)=\alpha_{m}(V) /\left(\alpha_{m}(V)+\beta_{m}(V)\right)$ & \\
\hline & $\alpha_{m}(V)=\frac{-0.1(V+35)}{\left(e^{-0.1(V+35)}-1\right)}$ & $\alpha_{h}(V)=0.07 e^{-(V+58) / 20}$ \\
\hline & $\beta_{m}(V)=4 e^{-(V+60) / 18}$ & $\beta_{h}(V)=1 /\left(e^{-0.1(V+28)}+1\right)$ \\
\hline \multirow[t]{2}{*}{$I_{K}=g_{K} n^{4}\left(V-E_{K}\right)$} & $\alpha_{n}(V)=\frac{-0.01(V+34)}{\left(e^{-0.1(V+34)}-1\right)}$ & \\
\hline & $\beta_{n}(V)=0.125 e^{-(V+44) / 80}$ & \\
\hline
\end{tabular}


Table 2 | The maximal conductances and reversal potential values corresponding to each of the neuron models.

\begin{tabular}{|c|c|c|c|c|c|c|c|c|c|c|}
\hline & \multicolumn{8}{|c|}{ Neocortex } & \multirow{3}{*}{$\begin{array}{c}\frac{\text { Thalamus }}{\text { TCR }} \\
\text { Cell } 9\end{array}$} & \multirow{3}{*}{$\frac{\frac{\text { Hippocampus }}{\text { RHI }}}{\text { Cell } 10}$} \\
\hline & \multicolumn{3}{|c|}{ RS cells } & \multicolumn{2}{|c|}{ FS cells } & \multicolumn{3}{|c|}{ IB cells } & & \\
\hline & Cell 1 & Cell 2 & Cell 3 & Cell 4 & Cell 5 & Cell 6 & Cell 7 & Cell 8 & & \\
\hline \multicolumn{11}{|c|}{ MAXIMAL CONDUCT. $\left(\mathrm{mS} / \mathrm{cm}^{2}\right)$} \\
\hline$g_{\text {leak }}$ & 0,1 & 0,0205 & 0,0133 & 0,15 & 0,038 & 0,01 & 0,01 & 0,1 & 0,05 & 0,1 \\
\hline$g_{\mathrm{Na}}$ & 50 & 56 & 10 & 50 & 58 & 50 & 50 & 50 & 3 & 35 \\
\hline$g_{K}$ & 5 & 6 & 21 & 10 & 3,9 & 5 & 5 & 4,2 & 5 & 9 \\
\hline$g_{M}$ & 0,07 & 0,075 & 0,098 & - & 0,0787 & 0,03 & 0,03 & 0,042 & - & - \\
\hline$g_{L}$ & - & - & - & - & - & 0,1 & 0,2 & 0,12 & - & - \\
\hline$g_{T}$ & - & - & - & - & - & - & - & - & 5 & 5 \\
\hline \multicolumn{11}{|c|}{ REVERSAL POTENTIAL (mV) } \\
\hline$E_{\text {leak }}$ & -70 & $-70,3$ & $-56,2$ & -70 & $-70,4$ & -70 & -70 & -75 & -70 & -65 \\
\hline$E_{\mathrm{Na}}$ & 50 & 50 & 50 & 50 & 50 & 50 & 50 & 50 & 50 & 55 \\
\hline$E_{K}$ & -90 & -90 & -90 & -90 & -90 & -90 & -90 & -90 & -90 & -90 \\
\hline$E_{C a}$ & - & - & - & - & - & 120 & 120 & 120 & - & - \\
\hline$E_{T}$ & - & - & - & - & - & - & - & - & 0 & - \\
\hline \multicolumn{11}{|c|}{ OTHER PARAM. } \\
\hline$V_{T}(\mathrm{mV})$ & $-61,5$ & $-56,2$ & $-65,4$ & $-61,5$ & -57.9 & $-56,2$ & $-56,2$ & -58 & - & - \\
\hline$V_{x}(\mathrm{mV})$ & - & - & - & - & - & - & - & - & - & 5 \\
\hline$\tau_{\max }(\mathrm{mS})$ & 4000 & 608 & 934 & - & 502 & 4000 & 4000 & 1000 & - & - \\
\hline$\phi$ & - & - & - & - & - & - & - & - & - & 5 \\
\hline$C(\mu F)$ & 0,29 & 1 & 1 & 0,14 & 1 & 0,29 & 0,29 & 0,29 & 1 & 1 \\
\hline
\end{tabular}

Other Parameters are also reported.

Cell 1: RS cell as observed from ferret visual cortex in vitro.

Cell 2: RS excitatory cell as observed from somatosensory cortex in vitro.

Cell 3: RS inhibitory cell as observed from somatosensory cortex in vitro.

Cell 4: FS cell as observed from ferret visual cortex in vitro.

Cell 5: FS cell as observed from somatosensory cortex in vitro.

Cell 6: IB cell as observed from guinea pig somatosensory cortex in vitro (Initial burst followed by adaptive action potentials).

Cell 7: IB cell as observed from guinea pig somatosensory cortex in vitro (Repetitive bursting).

Cell 8: IB cell as observed from cat visual cortex.

Cell 9: TCR cell as observed from Mouse thalamocortical relay neuron.

Cell 10: RHI cell as observed from Rat hippocampal interneuron.

Thus, the total derivative with respect to time of the above energy will be,

$$
\dot{H}(t)=C V \dot{V}+I_{l} E_{l}+I_{N_{a}} E_{N_{a}}+I_{K} E_{K}+I_{M} E_{K}+I_{L} E_{C a}+I_{T} E_{T} .
$$

where $E_{l}, E_{N a}, E_{K}$, and $E_{C a}$ are the Nernst potentials of leakage, the sodium, potassium and calcium ions in the resting state of the neuron. And $I_{l}, I_{N_{a}}, I_{K}\left(I_{M}\right), I_{L}$, and $I_{T}$ are the ion currents of leakage, sodium, potassium, and calcium given by,

$$
\begin{aligned}
I_{l}= & g_{l}\left(V-E_{l}\right), \\
I_{N_{a}}= & g_{N a} m^{3} h\left(V-E_{N a}\right), \\
I_{K}= & g_{K} n^{4}\left(V-E_{K}\right),\left(I_{K}=g_{K}(0.75(1-h))^{4}\left(V-E_{K}\right)\right. \\
& \quad \quad \quad \text { or TCR cell, }) \\
I_{M}= & g_{M} p\left(V-E_{K}\right), \\
I_{L}= & g_{L} q^{2} r\left(V-E_{C a}\right), \\
I_{T}= & g_{T} p_{\infty}^{2} r\left(V-E_{T}\right)
\end{aligned}
$$

Substituting Equation (1) in (3), we have for the energy rate in the circuit,

$$
\begin{aligned}
\dot{H}(t)= & V I_{S t i m}-I_{l}\left(V-E_{l}\right)-I_{N_{a}}\left(V-E_{N_{a}}\right)-I_{K}\left(V-E_{K}\right) \\
& -I_{M}\left(V-E_{K}\right)-I_{L}\left(V-E_{C a}\right)-I_{T}\left(V-E_{T}\right) .
\end{aligned}
$$

Finally, replacing in Equation (5) the ion currents by their expressions given by Equation (4), the electrochemical energy rate in each neuron will be given by,

$$
\dot{H}_{\text {cell }}=V I_{\text {Stim }}-\mathrm{E}_{\text {cell }},
$$

where cell=RS, FS, IB, TCR, RHI refers to the five conductancebased models considered in this work. This energy derivative provides the total derivative of the electrochemical energy in the neuron as a function of its state variables. The first term in the right hand summation represents the electrical power given to the neuron via the different junctions reaching the neuron and the $\mathrm{E}_{\text {cell }}$ represents the energy per second consumed by the ion channels (ion channels energy) involved in the dynamics 
of each cell model. The forms of the ion channels energies are given as:

$$
\begin{aligned}
\mathrm{E}_{R S}= & g_{l}\left(V-E_{l}\right)^{2}+g_{N_{a}} m^{3} h\left(V-E_{N_{a}}\right)^{2}+g_{K} n^{4}\left(V-E_{K}\right)^{2} \\
& +g_{M} p\left(V-E_{K}\right)^{2}, \\
\mathrm{E}_{F S}= & g_{l}\left(V-E_{l}\right)^{2}+g_{N_{a}} m^{3} h\left(V-E_{N_{a}}\right)^{2}+g_{K} n^{4}\left(V-E_{K}\right)^{2}, \\
\mathrm{E}_{I B}= & g_{l}\left(V-E_{l}\right)^{2}+g_{N_{a}} m^{3} h\left(V-E_{N_{a}}\right)^{2}+g_{K} n^{4}\left(V-E_{K}\right)^{2} \\
& +g_{M} p\left(V-E_{K}\right)^{2}+g_{L} q^{2} r\left(V-E_{C a}\right)^{2}, \\
\mathrm{E}_{T C R}= & g_{l}\left(V-E_{l}\right)^{2}+g_{N_{a}} m^{3} h\left(V-E_{N_{a}}\right)^{2} \\
& +g_{K}(0.75(1-h))\left(V-E_{K}\right)^{2}+g_{T} p_{\infty}^{2} r\left(V-E_{T}\right)^{2}, \\
\mathrm{E}_{H F I}= & g_{l}\left(V-E_{l}\right)^{2}+g_{N_{a}} m^{3} h\left(V-E_{N_{a}}\right)^{2} \\
& +g_{K} n^{4}\left(V-E_{K}\right)^{2},
\end{aligned}
$$

These equations permit evaluation of the total energy consumed by a given neuron and also give information about the consumption associated to each of the ionic channels. Fundamentally, for each cell, this rate of energy expressed in $\mathrm{nJ} / \mathrm{s}$ must be replenished by the ion pumps and metabolically supplied by hydrolysis of ATP molecules in order to maintain the cell's spiking activity.

\subsection{ION-COUNTING BASED ENERGY CONSUMPTION}

The energy consumption can be also computed based on the amount of $\mathrm{Na}^{+}$load $\left(Q_{N_{a}}\right)$ crossing the membrane during a single action potential, which it can be estimated integrating the area under the total $\mathrm{Na}^{+}$current curve (see Figure 2) for the duration of stimulus presentation.

Since the $\mathrm{Na}^{+}$gradient is maintained primarily by the activity of the $\mathrm{Na}^{+} / \mathrm{K}^{+}$ATPase which mediates influx of $2 \mathrm{~K}^{+}$in exchange for $3 \mathrm{Na}^{+}$per one ATP molecule consumed, the number of ATP moles (ATPmols) can be computed as $\frac{Q_{N a}}{3 \mathrm{eNA}}$, where $\mathrm{e}=1.60210^{-19} \mathrm{C}$ is the electric charge and NA $=6.02210^{23}$ is the Avogadro constant (Attwell and Laughlin, 2001). For the other hand, the energy available for chemical work from the ATP concentration is measured by the free energy of ATP hydrolysis $\left(F_{A T P}\right)$. This allows an estimate of the metabolic energy associated with ionic pumping as the free energy times the number of ATP moles, that is, $F_{A T P} *$ ATPmols.

The value of the free energy depends to some extent on the internal chemical state of the cell, and it has been reported to be in the range from 46 to $62 \mathrm{~kJ} / \mathrm{mol}$ of ATP (Jansen et al, 2003), but in this work, we set $F_{A T P}=50 \mathrm{~kJ} / \mathrm{mol}$.

Moreover, the integral of the area under the instantaneous energy function for a given cell (Equation 7) provides an estimate of the neuron energy, which is used to computed the efficiency of the ATP hydrolysis as the ratio of that energy consumption to the number of ATP moles, that is, $\frac{1}{\text { ATPmols }} \int E_{\text {cell }}$. This ratio expressed is $\mathrm{kJ} / \mathrm{mol}$ gives us the opportunity to check if our method of calculation of the actual energy consumption by the pump and the number of ATP molecules involved are consistent with other data in the literature. The calculated values of this ratio are reported in Figures 3, 6 as hydrolysis of ATP molecules.

\section{RESULTS}

\subsection{FIRING CHARACTERISTICS OF ACTION POTENTIALS}

The different possible combinations of conductances in the neuron models considered in this work give origin to a variety of action potentials with different waveforms and firing characteristics. Figure 1 reports, in part (A), trains of action potentials from different neuron models when exposed to prolonged stimuli of constant magnitude slightly greater than threshold (see Table 3 for a description of the current stimuli values). The inter-spike firing frequencies calculated from the inter-spike time intervals are reported in parts $(\mathbf{B}, \mathbf{C})$. As it can be seen, of all regular-spiking cells, the RS cell from ferret visual cortex (Cell 1) exhibits the most pronounced adaptation with an inter-spike firing frequency declining from about $62-3.5 \mathrm{~Hz}$. Likewise, the IB cell as recorded respectively from guinea pig somatosensory cortex (Cell 6) and cat visual cortex (Cell 8), initially generate action potentials at high firing frequency (of about $55 \mathrm{~Hz}$ ) that decreases rapidly to low values within a short time span. Meanwhile, the repetitive IB cell from guinea pig somatosensory cortex (Cell 7) shows repetitive intrinsic bursting with a mean inter-burst frequency of about $1 \mathrm{~Hz}$, and an inter-spike frequency ranging from 300 to $150 \mathrm{~Hz}$. The others cell models (i.e., Cells 4, 5, 9, and 10) respond to depolarizing stimuli by generating action potentials with little or no adaptation.

\subsection{EFFICIENT ACTION POTENTIALS AND OVERLAPPING}

Figure 2 shows in part (A) the shape of the sodium (in blue line) and potassium currents corresponding to a particular action potential of the previously described trains. The sodium current (in blue line) is negative but has been depicted with a positive sign for a better appreciation of the great extent of its overlapping with the potassium current (red line). Note that as sodium and potassium currents are both of positive charges but moving in opposite directions of the cell's membrane they neutralize each other to the extent of their mutual overlap. The sodium charge that is not counterbalanced by simultaneously flowing potassium charge is much smaller for a greater overlap. This unbalanced load corresponds to the minimum charge $\left(Q_{\min }\right)$ needed for the depolarization of the action potential. The sum of this capacitive minimum and the overlap load gives the total $\mathrm{Na}^{+}$loads per action potential. Recollected values are depicted in Figure 2B.

To quantify the sodium and potassium currents overlap we calculated the dimensionless charge separation as the ratio of the capacitive minimum and the total $\mathrm{Na}^{+}$charge per action potential. That is, $Q_{\text {Separation }}=Q_{\min } / Q_{N a}$, this measure allows quantifying how efficiently sodium flux is used for action potential depolarization (Alle et al., 2009). In view of the above, it seems that rat hippocampal interneuron (Cell 10) and mouse thalamocortical relay neuron (Cell 9) are the most efficient in generating action potentials with a charge separation approaching $80 \%$, which shows that most of sodium load are confined to the rising phase of the action potential. For the other hand, the FS cell from a ferret Visual Cortex (Cell 4) and the repetitive IB cell from a guinea pig somatosensory cortex in vitro (Cell 7) are the most inefficient with only $14 \%$ of sodium entry used for spike depolarization. In fact, the sodium influx during an action potential in thalamocortical relay neuron was $69 \mathrm{nC} / \mathrm{cm}^{2}$, consuming 

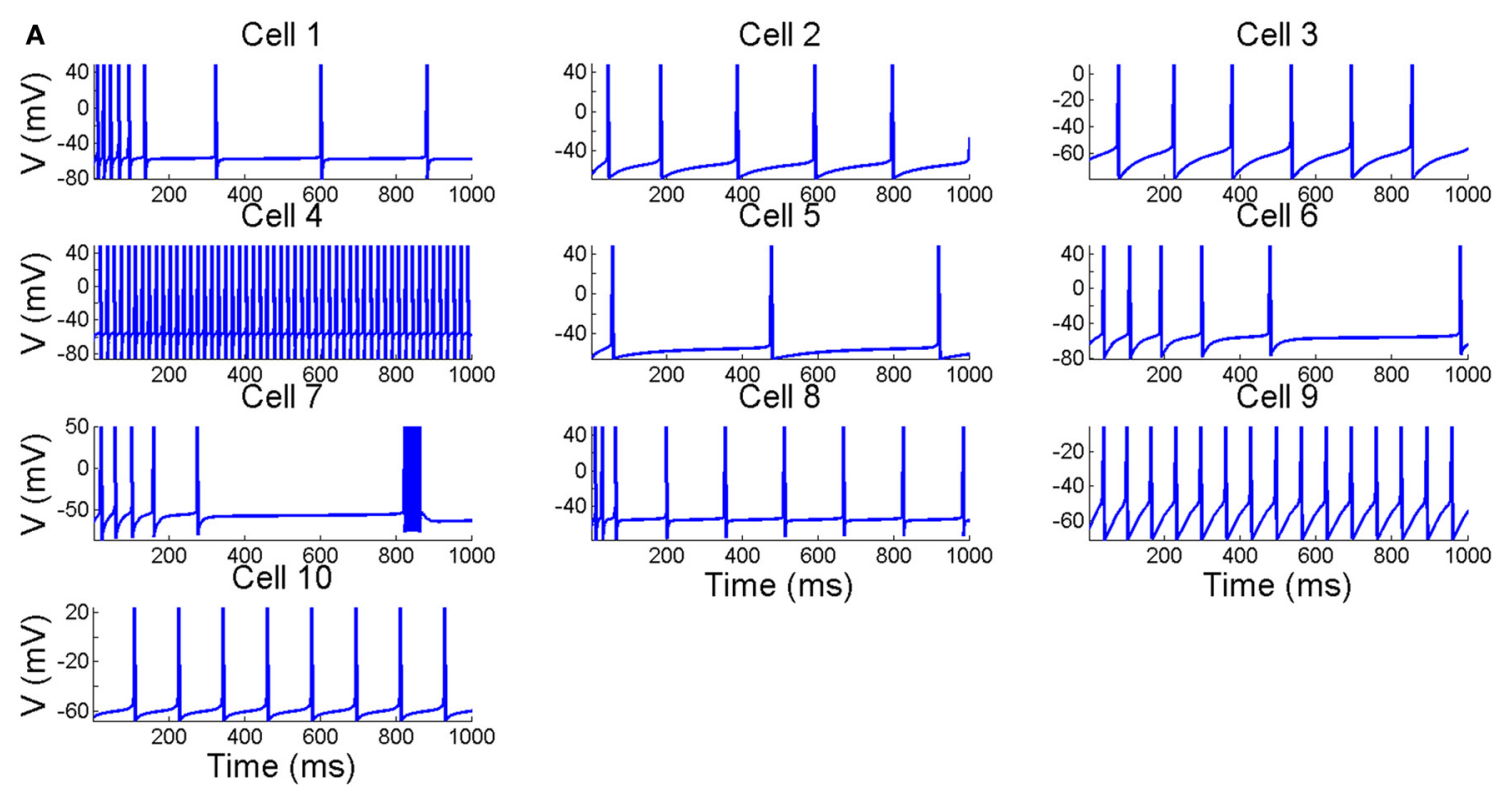

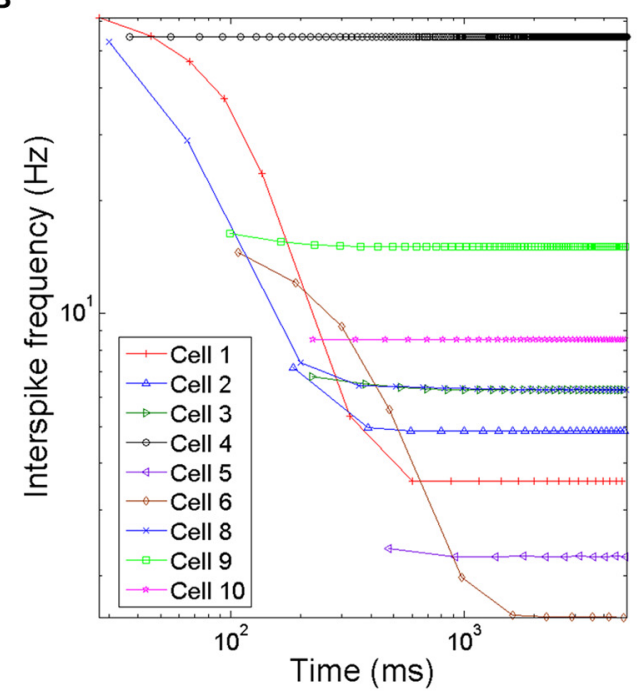

c

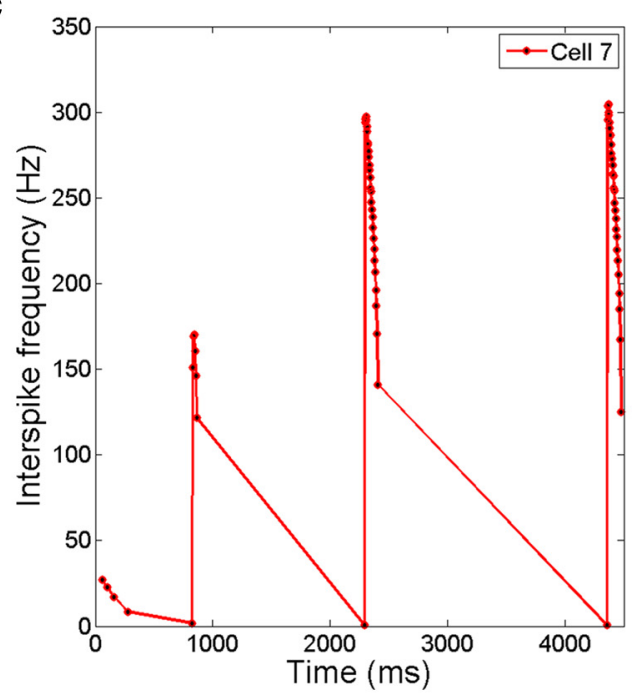

FIGURE 1 | (A) Time course of membrane voltage from different spiking cells when stimulated by prolonged depolarizing stimulus slightly greater than threshold. The values of stimuli in $\left(\mu \mathrm{A} / \mathrm{cm}^{2}\right)$ are reported in Table 3. (B,C) The interspike firing frequencies calculated from the interspike intervals as a function of time.

$0.24 \mathrm{pmol} / \mathrm{cm}^{2}$ of ATP molecules per spike, while the FS cell from somatosensory cortex moves $217 \mathrm{nC} / \mathrm{cm}^{2}$ of sodium ions per spike consuming $0.75 \mathrm{pmol} / \mathrm{cm}^{2}$ of ATP molecules. Other models including RS cells from somatosensory cortex (Cell 2) and ferret visual cortex (Cell 1) show high values of $\mathrm{Na}^{+}$loads of about $207 \mathrm{nC} / \mathrm{cm}^{2}\left(0.72\right.$ ATP $\left.\mathrm{pmol} / \mathrm{cm}^{2}\right)$ and $174 \mathrm{nC} / \mathrm{cm}^{2}(0.60$ ATP $\left.\mathrm{pmol} / \mathrm{cm}^{2}\right)$, respectively. These estimates agree with other data reported in literature (Alle et al., 2009; Carter and Bean, 2009; Sengupta et al., 2010).

\subsection{ENERGY}

Assuming that one ATP molecule hydrolyzed under normal physiological conditions liberates of about $50 \mathrm{~kJ} / \mathrm{mol}$, our calculations of the energy demands in $\mathrm{nJ}$ per $\mathrm{cm}^{2}$ based on the ion-counting method give energy consumptions ranging from $12 \mathrm{~nJ} / \mathrm{cm}^{2}$ for a thalamocortical relay cell (Cell 9) to $38 \mathrm{~nJ} / \mathrm{cm}^{2}$ for a FS cell from somatosensory cortex (Cell 5).

For the other hand, following the ion-channels energy functions described in Equation (7), the calculated values of the energy consumption give results which are in excellent agreement with those computed according to ion-counting approach. Indeed, according to the Wilcoxon rank-sum test (Gibbons and Chakraborti, 2011) performed on the data reported in Table 3, the difference between the values of metabolic and ionic energy is statistically not significant at the $5 \%$ significance level with a $p$-value $=0.8194$.

The values of the energy consumption needed for the restoration of concentration gradients after an action potential was determined by integrating over long period of time the area under the instantaneous ion channels energy curve divided by the 
Table 3 | lonic flux and energy demands of single action potentials from different spiking cells when stimulated by prolonged current stimulus slightly greater than threshold.

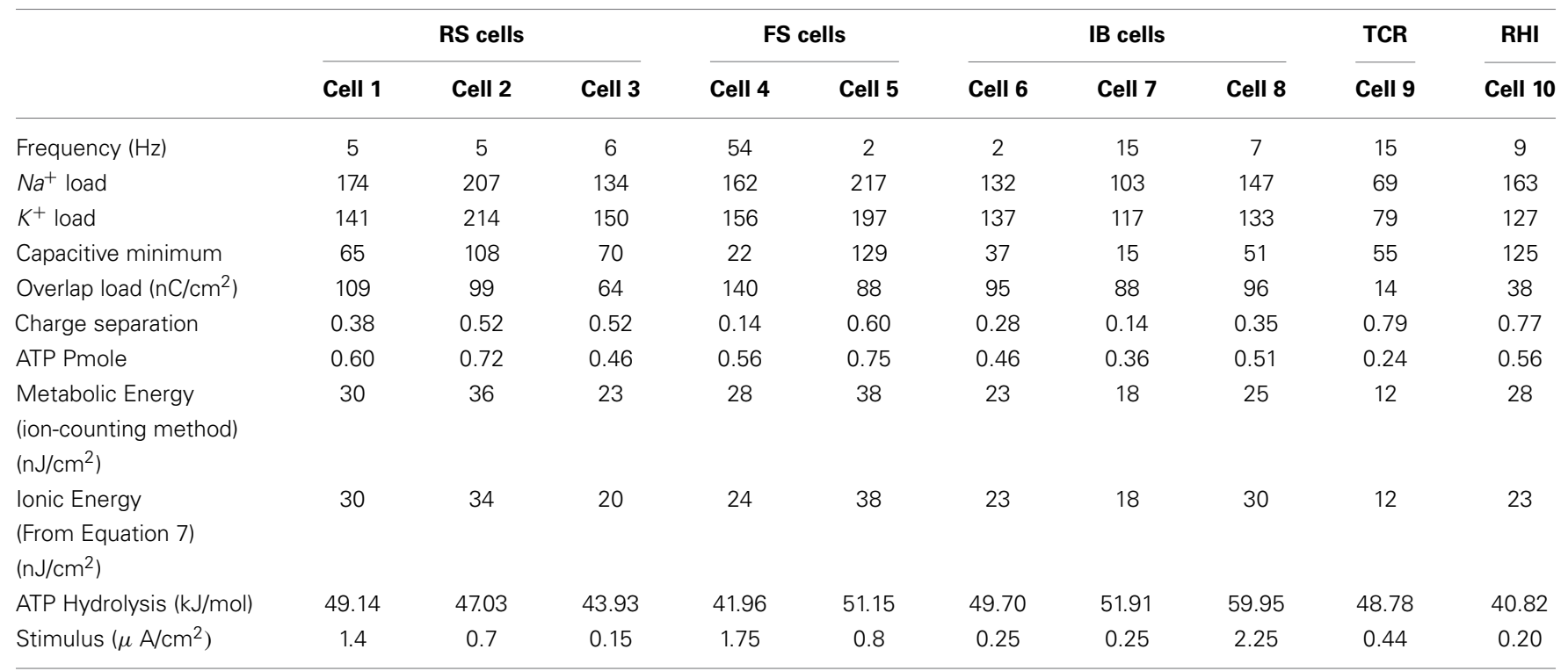

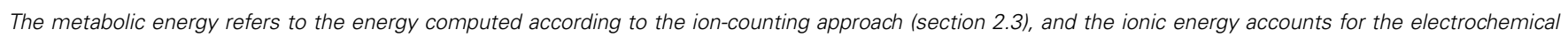
energy computed as the integral of the energy functions given by Equation (7).

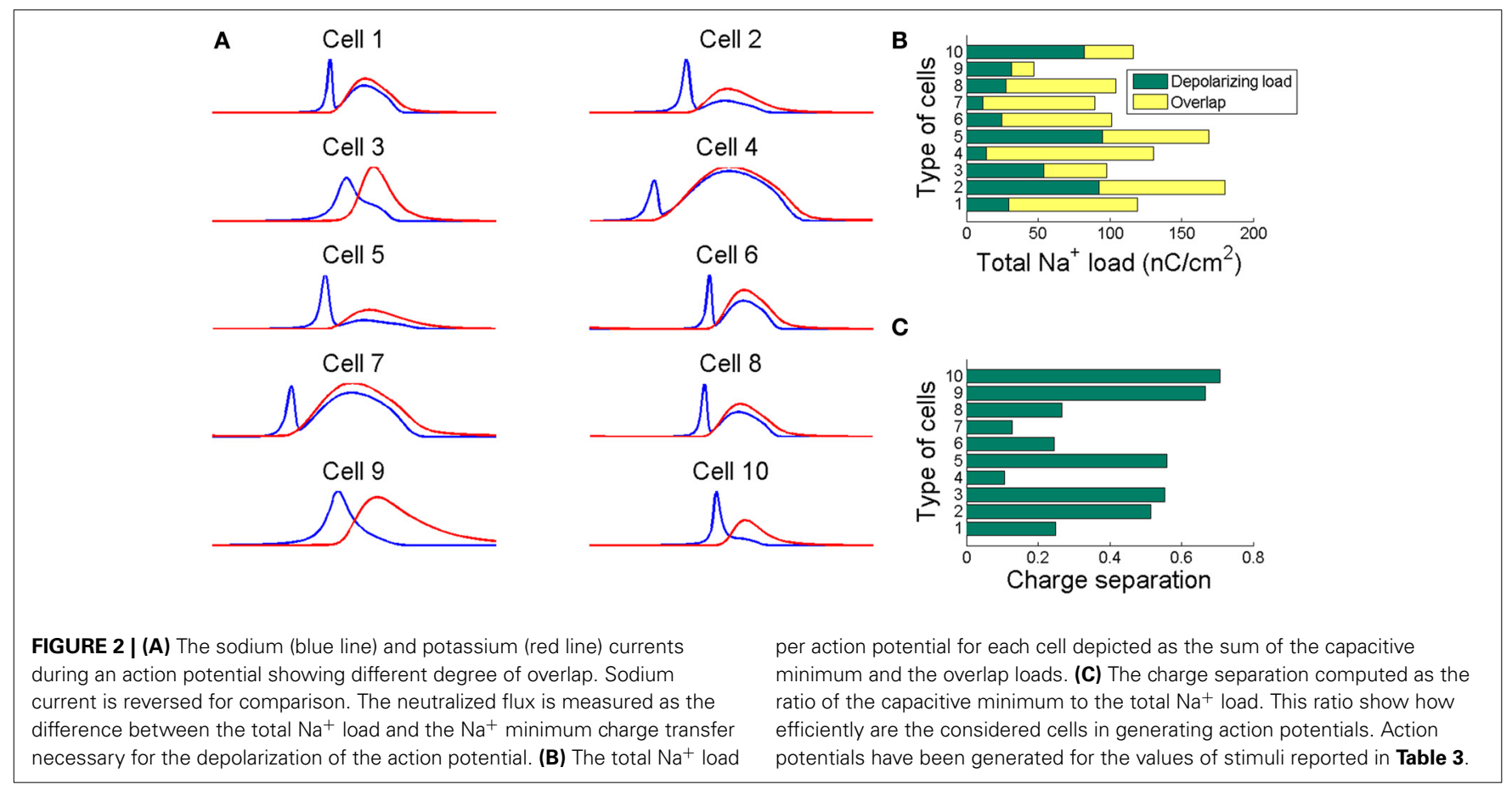

number of spikes, which gives the energy consumption of a single spike. In Figure 3 we report the free energy of ATP hydrolysis computed as the ration of the ionic energy and the number of ATP molecules. This ratio is expressed in $\mathrm{kJ} / \mathrm{mol}$ and gives values ranging from $40.82 \mathrm{~kJ} / \mathrm{mol}$ in the case of a rat hippocampal interneuron (Cell 10) and value of about $60 \mathrm{~kJ} / \mathrm{mol}$ for an IB cells as observed from cat visual cortex (Cell 8). These values are in nice agreement with the values of the free energy of ATP hydrolysis reported in the literature (Ereciriska et al, 1989; Jansen et al, 2003).

\subsection{TEMPERATURE AND STIMULUS INTENSITY}

Because neural properties are temperature dependent, we have analyzed in more detail the values of energy consumption and the free energy of ATP hydrolysis as a function of temperature and the magnitude of the external stimuli. Varying the cell temperature in 


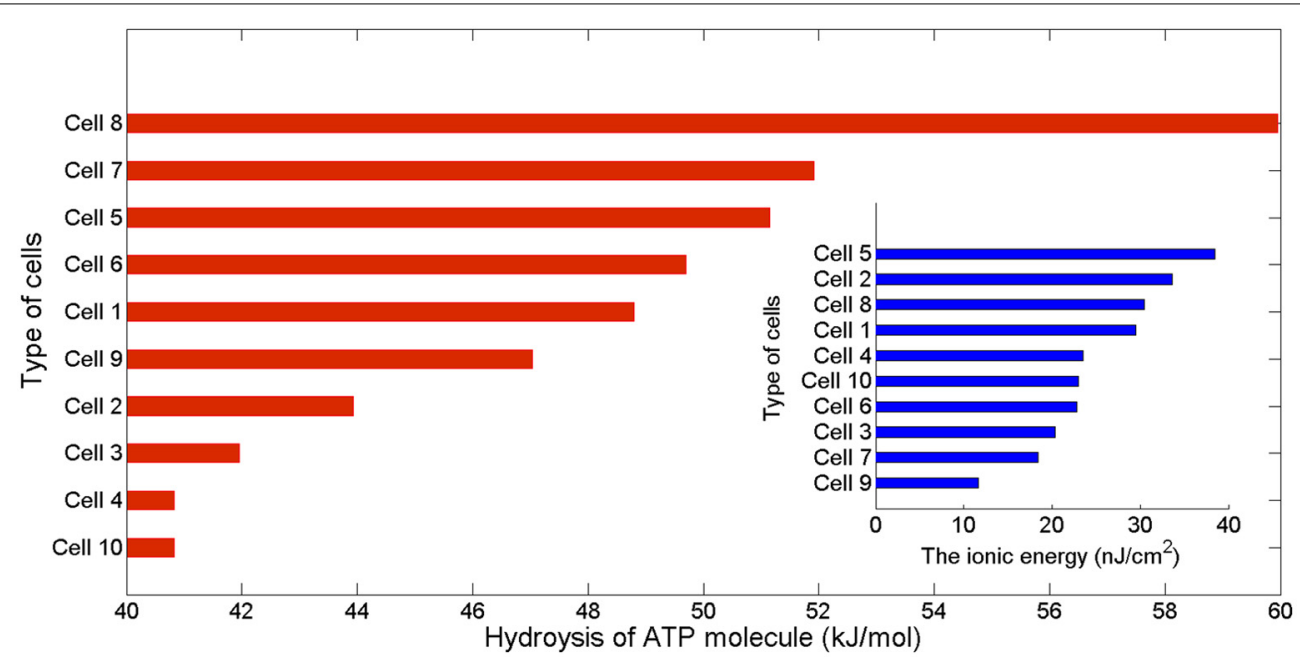

FIGURE 3 | The free energy of ATP hydrolysis in $\mathrm{kJ} / \mathrm{mol}$ computed as the ratio of the ionic energy and the number in mole of ATP molecules per membrane unit area. The values of the free energy liberated range from
$40.82 \mathrm{~kJ} / \mathrm{mol}$ in the case of the rat hippocampal interneuron to $59.95 \mathrm{~kJ} / \mathrm{mol}$ in the intrinsically bursting cell from a cat visual cortex. The inset displays the corresponding values of ionic energy in $\mathrm{nJ}$ per $\mathrm{cm}^{2}$ calculated from Equation (7). the neuron models was down multiplying the rates of change of the activation and inactivation gating variables by a factor $k=$ $2.78^{(\mathrm{Temp}-36) / 10}$, and considering a range of temperature between $20^{\circ} \mathrm{C}$ and $40^{\circ} \mathrm{C}$. The stimuli were varied from 2.25 to $10 \mu \mathrm{A} / \mathrm{cm}^{2}$.

The contour plots in Figure 5 show, for each cell, how the energy consumption in $\mathrm{nJ} / \mathrm{cm}^{2}$ per spike depends upon cell temperature and input stimulus. As it can be seen the lowest energy consumption values are achieved for higher temperatures. In fact, the increased firing frequencies induced by higher temperatures and stimulus (see Figure 4) imply more efficient use of sodium entry due mainly to the reduced overlap load between inward $\mathrm{Na}^{+}$current and outward $\mathrm{K}^{+}$current (Moujahid et al., 2012). Indeed, for all cells, the overlap load undergoes a reduction of about $90 \%$ with an increase of cell temperature in a wide range of stimulus intensity. This efficient use of sodium entry is usually accompanied by a reduction of the energy demands needed for the restoration of concentration gradients. For example, the rat hippocampal interneuron (Cell 10) at $20^{\circ} \mathrm{C}$ and an input stimulus of $2.25 \mu \mathrm{A} / \mathrm{cm}^{2}$ fires spikes at $55 \mathrm{~Hz}$ and consumes of about $58 \mathrm{~nJ} / \mathrm{cm}^{2}$. While at a higher temperature of about $40^{\circ} \mathrm{C}$ for a wide range of stimulus intensity, the energy consumption is about 5fold lower that the energy needed at low temperatures. This 5 -fold decrease in energy consumption corresponds to 7 -fold increase in firing frequency for an input stimulus of $10 \mu \mathrm{A} / \mathrm{cm}^{2}$. Likewise, the IB cell as observed from cat visual cortex (Cell 8) consumes of about $109 \mathrm{~nJ} / \mathrm{cm}^{2}$ at $20^{\circ} \mathrm{C}$ and lower stimulus, however, at $40^{\circ} \mathrm{C}$ it requires only $13 \mathrm{~nJ} / \mathrm{cm}^{2}$ which represents of about 8 -fold decrease in its energy demand. At this temperature the values of energy consumption are maintained for a wide range of input stimulus.

\subsection{THE FREE ENERGY OF ATP HYDROLYSIS}

Figure 6 shows the calculated values of ATP hydrolysis in $\mathrm{kJ} / \mathrm{mol}$ as a function of temperature and stimulus intensity. In this case, we observe different patterns depending on the cells type. The RS and FS cells at higher temperatures and high input stimuli liberate, respectively of about $12 \%$ and $10 \%$ more free energy than at lower temperatures. For these cells the values of free energy liberated range from $40.73 \mathrm{~kJ} / \mathrm{mol}$ in the case of FS cell from a ferret Visual Cortex (Cell 4 ) to $47.74 \mathrm{~kJ} / \mathrm{mol}$ in an inhibitory RS cell from somatosensory cortex in vitro (Cell 3 ). The IB cells in guinea pig somatosensory cortex (Cells 6 and 7) show similar pattern as observed in regular and fast spiking cells, but in this case, increasing the cell temperature and stimulus intensity cause the free energy to experience an increase of more than $17 \%$ reaching values of about $52.27 \mathrm{~kJ} / \mathrm{mol}$. But, the more sensible cells to temperature and stimulus changes are IB cells as observed from cat visual cortex (Cell 8) and mouse thalamocortical relay neuron (Cell 9). Cell 8 shows values of free energy that range from $44.58 \mathrm{~kJ} / \mathrm{mol}$ to $61.21 \mathrm{~kJ} / \mathrm{mol}$ representing an increase of about $37 \%$. For this cell, the higher values of free energy are achieved for higher temperatures and low values of stimulus. In fact, the more pronounced pattern was observed for values of stimulus below $3 \mu \mathrm{A} / \mathrm{cm}^{2}$, and a further increase of stimulus has seems to have little effect on free energy values. Conversely, Cell 9 accounting for a mouse thalamocortical relay neuron appears to be more sensitive to stimulus intensity than to temperature values. Increasing stimulus intensity from 2.25 to $10 \mu \mathrm{A} / \mathrm{cm}^{2}$ moves the cell to liberate of about $22 \%$ more free energy of ATP hydrolysis. Finally, for Cell 10 corresponding to a rat hippocampal interneuron, we can see that for values of input stimulus below $8 \mu \mathrm{A} / \mathrm{cm}^{2}$, the free energy shows an hyperbole surface with a maximum around $33^{\circ} \mathrm{C}$.

\section{DISCUSSIONS}

Based on three computational neuron models (see Table 1), we used different combinations of voltage-dependent conductances to reproduce a variety of action potentials with different waveforms and firing characteristics as recorded from different cells in the neocortex, thalamus and hippocampus. Initially, each cell was stimulated by prolonged depolarizing stimulus slightly greater than threshold. We calculated in $\mathrm{nC} / \mathrm{cm}^{2}$ the amount of $\mathrm{Na}^{+}$ load crossing the membrane during a single action potential 


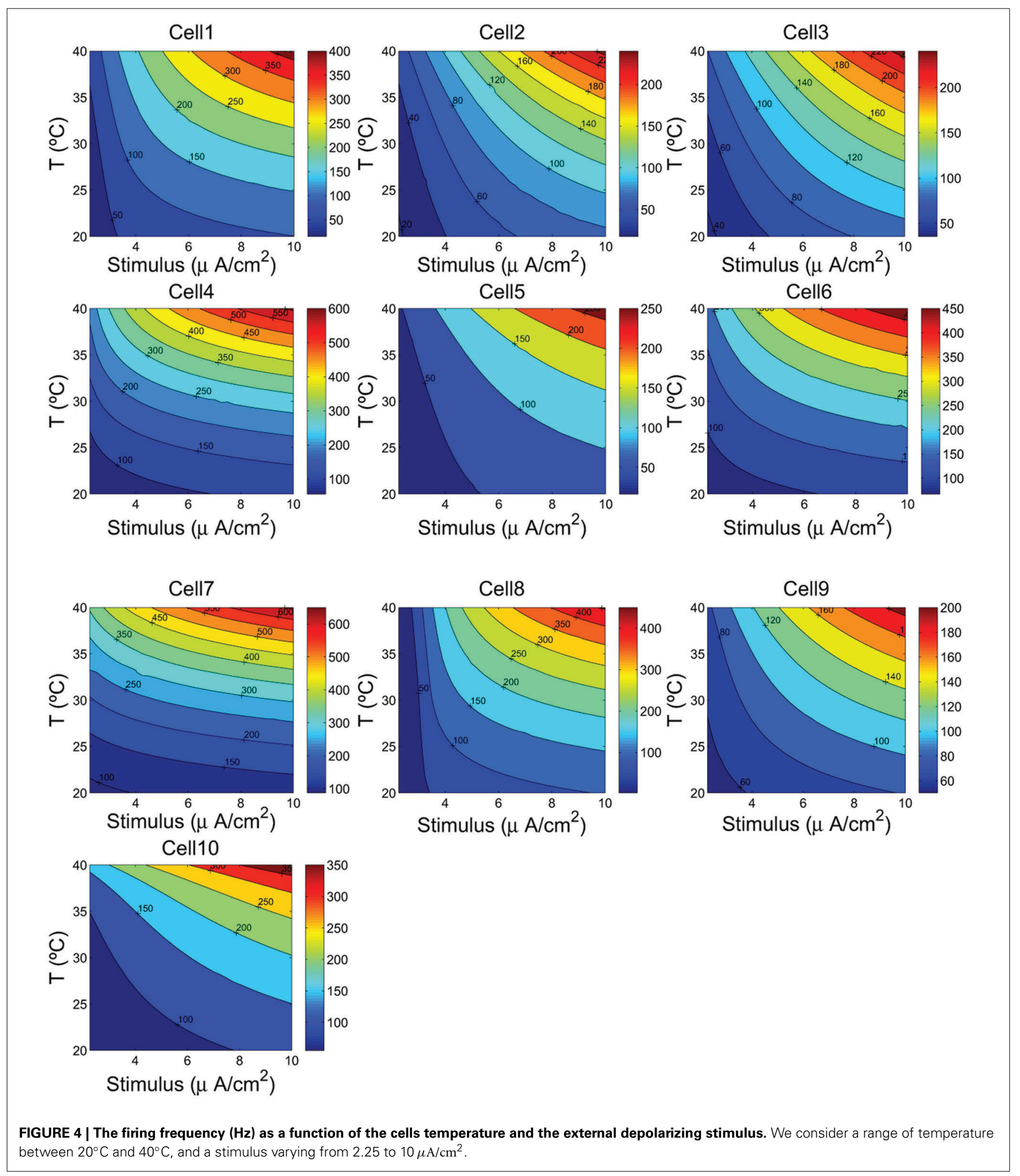

and the corresponding metabolic energy $\mathrm{nJ} / \mathrm{cm}^{2}$ needed for the restoration of concentration gradients after an action potential following two different approaches (see section 2). According to our calculations, for all the cells considered in this work, these two approaches have led to similar values of energy demands which confirms the consistency of our method to estimate the metabolic consumption. In fact, the range of values of our estimations of the free energy of ATP hydrolysis (see Figures 3,6 ) agree with other data reported in the literature (Ereciriska et al, 1989; Jansen et al, 2003). 


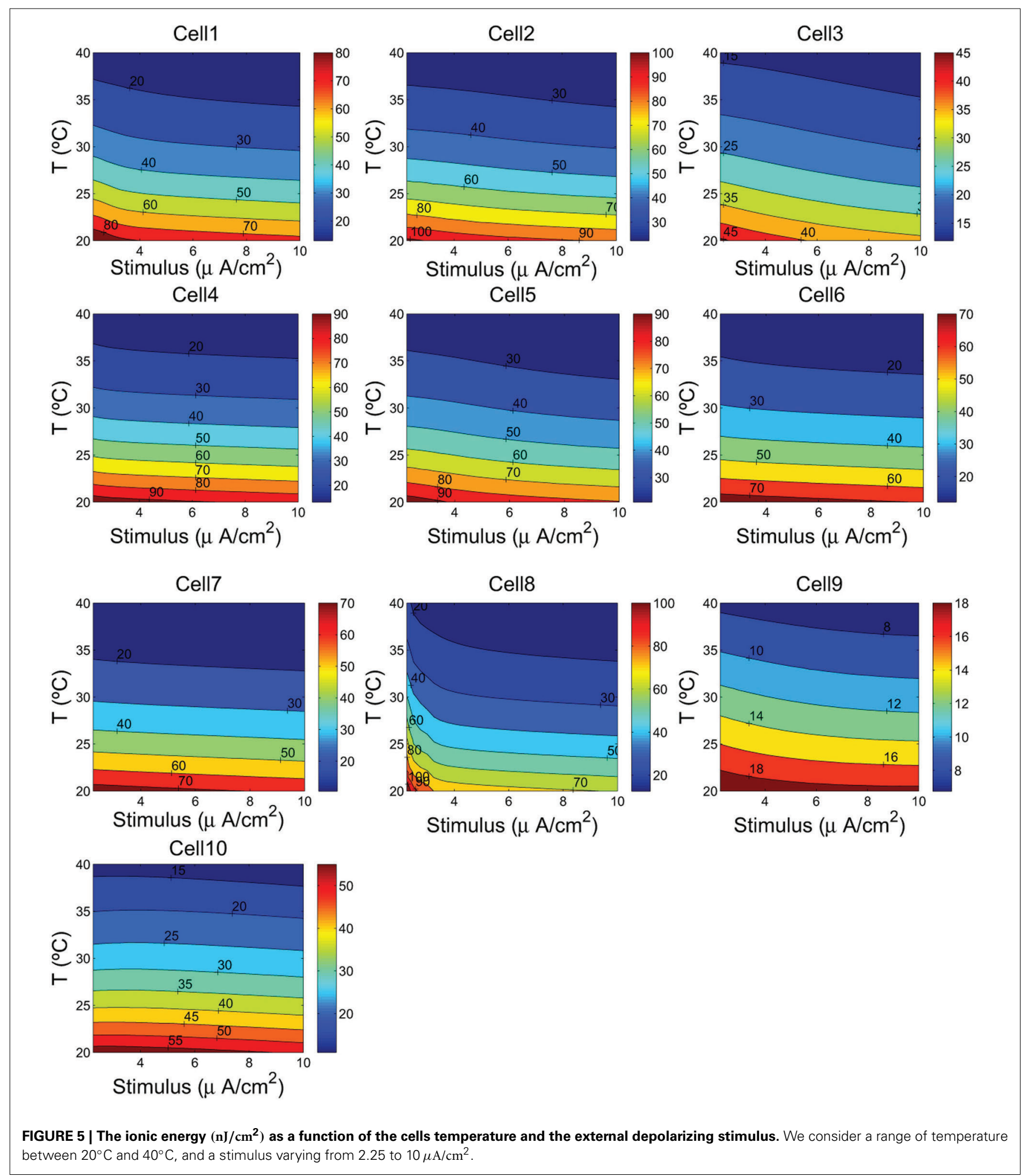

An initial classification of the different cells (see Table 3, Figure 3) places the thalamocortical relay cell (Cell 9) as the most energy-efficient cell consuming $12 \mathrm{~nJ} / \mathrm{cm}^{2}$ for each spike generated and liberating a free energy of ATP hydrolysis of about
$48.78 \mathrm{~kJ} / \mathrm{mol}$. For the other hand, the FS cell from somatosensory cortex (Cell 5) is the least energy-efficient requiring $38 \mathrm{~nJ} / \mathrm{cm}^{2}$ per spike and liberating $51.15 \mathrm{~kJ} / \mathrm{mol}$ of free energy from ATP hydrolysis. 

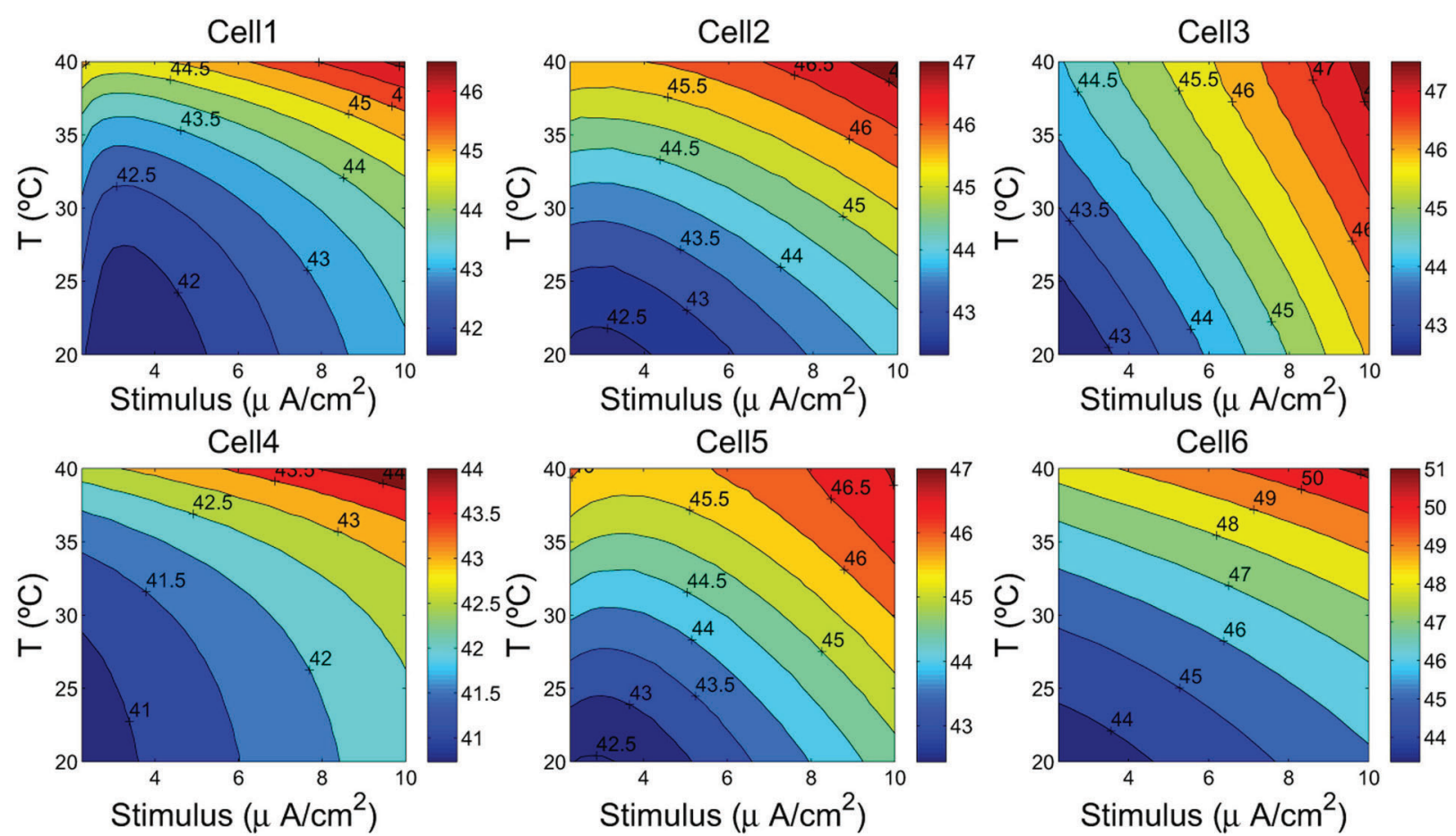

Cell5
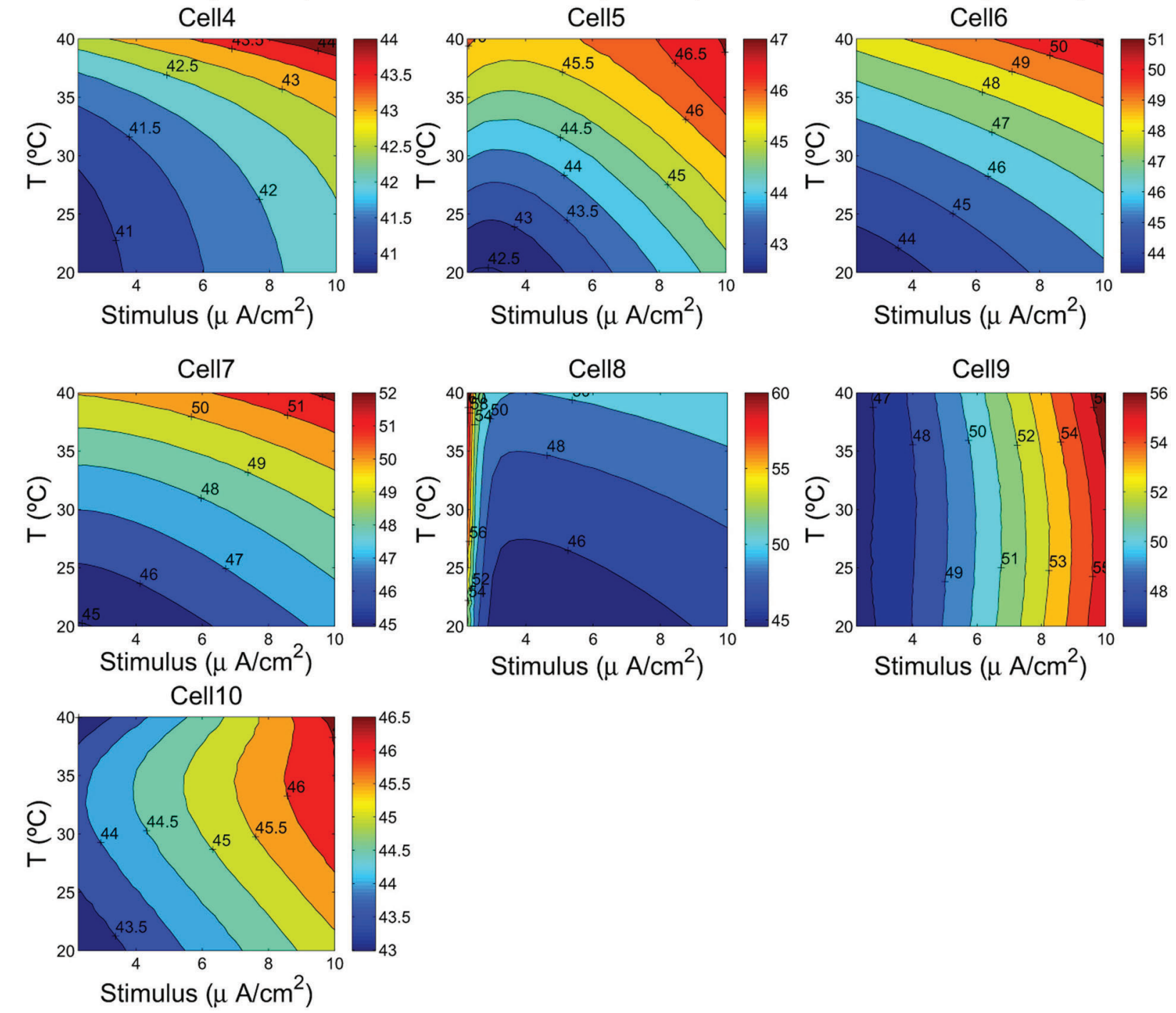

FIGURE 6 | Hydrolysis of ATP molecule in $\mathbf{~} \mathbf{J} / \mathbf{m o l}$ as a function of the cells temperature and the external depolarizing stimulus. We consider a range of temperature between $20^{\circ} \mathrm{C}$ and $40^{\circ} \mathrm{C}$, and a stimulus varying from 2.25 to $10 \mu \mathrm{A} / \mathrm{cm}^{2}$.

To quantify how the energy consumption in $\mathrm{nJ} / \mathrm{cm}^{2}$ and then the free energy of ATP hydrolysis depend upon cell temperature and input stimulus, we analyzed in more detail the values of these measures for a wide range of cell temperatures and stimulus intensities. The results give a clear evidence that the metabolic energy associated to the generation of action potentials is higher at lower temperature. Indeed, the spiking activity of the cells at higher temperatures involves less ion flux during the generation of an action potential. In all the neurons studied in this work, increasing the cell temperature from $20^{\circ} \mathrm{C}$ to $40^{\circ} \mathrm{C}$ resulted in 
decreases by about $80 \%$ in both the sodium and potassium flux. Obviously, this decrease in ion flux should be accompanied by a decrease in energy consumption. In fact, results reported in Figure 5 support this conjecture showing that low values of energy are achieved at higher temperatures. For a given temperature and stimulus intensity, for example, at $36^{\circ} \mathrm{C}$ and a stimulus value of $7 \mu \mathrm{A} / \mathrm{cm}^{2}$, the energy consumptions range from $8.42 \mathrm{~nJ} / \mathrm{cm}^{2}$ in the case of cell 9 to $26.8 \mathrm{~nJ} / \mathrm{cm}^{2}$ in the case of cell 5 and $28.5 \mathrm{~nJ} / \mathrm{cm}^{2}$ in cell 2 . The other cells show value of energy between 15 and $19 \mathrm{~nJ} / \mathrm{cm}^{2}$. While at $40^{\circ} \mathrm{C}$ and maintaining the same input stimulus $\left(7 \mu \mathrm{A} / \mathrm{cm}^{2}\right)$ the values of energy consumptions reported above decreased by $17 \%$.

The approach reported in this work, contrary to ion-countingbased methods (Attwell and Laughlin, 2001; Lennie, 2003), does not require ion counting for estimating the metabolic energy consumption of the generation of action potentials, and gives us the opportunity to check in neuron models described by Hodgkin-Huxley type kinetics which ion counting gives the correct metabolic energy consumption.

On the other hand, since in many areas of the brain neurons are organized in populations of units with similar properties, it should be of interest to know about the metabolic cost of information processing of large population of interconnected neurons. For this end, we need to combine experimental studies of nervous systems with numerical simulation of large-scale brain models. Our approach to find an energy function that quantifies the physical energy associated to the states of a generic model neuron described by differential equations could be of great interest when studying population of coupled neurons.

\section{ACKNOWLEDGMENTS}

Authors received support from UFI11/07 of the UPV/EHU, SandS project EU grant agreement 317947, MECCO projects TIN201128753-C02-02, TIN2011-23823, which are partially funded by FEDER.

\section{REFERENCES}

Alle, H., Roth, A., and Geiger, J. R. P. (2009). Energy-efficient action potentials in hippocampal mossy fibers. Science 325, 1405-1408. doi: 10.1126/science. 1174331

Ames, A. III. (2000). CNS energy metabolism as related to function. Brain Res. Rev. 34, 42-68. doi: 10.1016/S0165-0173(00)00038-2

Attwell, D., and Laughlin, S. B. (2001). An energy budget for signaling in the grey matter of the brain. J. Cereb. Blood Flow Metab. 21, 1133-1145. doi: 10.1097/00004647-200110000-00001

Buzsaki, G., Kaila, K., and Raichle, M. (2007). Inhibition and brain work. Neuron 56, 771-783. doi: 10.1016/j.neuron.2007.11.008

Carter, B. C., and Bean, B. P. (2009). Sodium entry during action potentials of mammalian neurons: incomplete inactivation and reduced metabolic efficiency in fast-spiking neurons. Neuron 64, 898-909. doi: 10.1016/j.neuron.2009.12.011

Cauli, B., Audinat, E., Lambolez, B., Angulo, M. C., Ropert, N., Tsuzuki, K., et al. (1997). Molecular and physiological diversity of cortical non pyramidal cells. J. Neurosci. 17, 3894-3906.

Crotty, P., Sangrey, T., and Levy, W. B. (2006). Metabolic energy cost of action potential velocity. J. Neurophysiol. 96, 1237-1246. doi: 10.1152/jn.01204.2005

Ereciriska, M., and Silver, I. A. (1989). ATP and brain function. J. Cereb. Blood Flow Metab. 9, 2-19. doi: 10.1038/jcbfm.1989.2

Gibbons, J. D., and Chakraborti, S. (2011). Nonparametric Statistical Inference, 5th Edn. Boca Raton, FL: Chapman and Hall-CRC Press, Taylor and Francis Group.

Guo, Y., Rubin, J. E., McIntyre, C. C., Vitek, J. L., and Terman, D. (2008). Thalamocortical relay fidelity varies across subthalamic nucleus deep brain stimulation protocols in a data-driven computational model. J. Neurophysiol. 99, 1477-1492. doi: 10.1152/jn.01080.2007

Hertz, L., Junnan, X., Dan, S., Enzhi, Y., Li, G., and Liang, P. (2013). Astrocytic and neuronal accumulation of elevated extracellular $\mathrm{K}+$ with a $2 / 3 \mathrm{~K}+\mathrm{Na}+$ flux ratio - consequences for energy metabolism, osmolarity and higher brain function Front. Comput. Neurosci. 7:114. doi: 10.3389/fncom.2013.00114

Hodgkin, A. L. (1975). The optimum density of sodium channels in an unmelinated nerve. Philos. Trans. R. Soc. B Biol. Sci. 270, 297-300.

Hodgkin, A. L., and Huxley, A. F. (1952). A quantitative description of membrane current and its application to conduction and excitation in nerve. J. Physiol. 117, 500-544.

Jansen, M. A., Shen, H., Zhang, L., Wolkowicz, P. E., and Balschi, J. A. (2003). Energy requirements for the $\mathrm{Na}+$ gradient in the oxygenated isolated heart: effect of changing the free energy of ATP hydrolysis. Am. J. Physiol. Heart Circ. Physiol. 285, H2437-H2445. doi: 10.1152/ajpheart.00534.2003

Kandel, E. R., Schwartz, J. H., and Jessell, T. M. (1991). Principles of Neural Science, $3 r d$ edn. Norwalk: Appleton and Lange.

Laughlin, S. B., de Ruyter van Steveninck, R. R., and Anderson, J. C. (1998). The metabolic cost of neural information. Nat. Neurosci. 1, 36-41. doi: 10.1038/236

Lennie, P. (2003). The cost of cortical computation. Curr. Biol. 13, 493-497. doi: 10.1016/S0960-9822(03)00135-0

Moujahid, A., and d'Anjou, A. (2012). Metabolic efficiency with fast spiking in the squid axon. Front. Comput. Neurosci. 6:95. doi: 10.3389/fncom.2012.00095

Moujahid, A., d'Anjou, A., Torrealdea, F., and Torrealdea, F. J. (2010). "Energetic considerations on the dynamics of Hodgkin-Huxley neurons," in 6th International Conference on Natural Computation (ICNC), Vol. 6 (Shandong), 3156-3163. doi: 10.1109/ICNC.2010.5584454

Moujahid, A., d'Anjou, A., Torrealdea, F. J., and Torrealdea, F. (2011). Energy and information in Hodgkin-Huxley neurons. Phys. Rev. E 83:031912. doi 10.1103/PhysRevE.83.031912

Peters, A., and Jones, E. G. (1984). Components of the Cerebral Cortex. New York, NY: Plenum.

Pospischil, M., Toledo-Rodriguez, M., Monier, C., Piwkowska, Z., Bal, T., Frégnac, Y., et al. (2008). Minimal Hodgkin-Huxley type models for different classes of cortical and thalamic neurons. Biol. Cybern. 99, 427-441. doi: 10.1007/s00422008-0263-8

Sengupta, B., Stemmler, M., Laughlin, S. B., and Niven, J. E. (2010). Action potential energy efficiency varies among neuron types in vertebrates and invertebrates. PLoS Comput. Biol. 6:e1000840. doi: 10.1371/journal.pcbi.1000840

Sohal, V. S., and Huguenard, J. R. (2002). Reciprocal inhibition controls the oscillatory state in thalamic networks. Neurocomputing 44-46, 653-659. doi: 10.1016/S0925-2312(02)00453-8

Stein, W. D. (2002). Cell volume homeostasis: ionic and nonionic mechanisms. The sodium pump in the emergence of animal cells. Int. Rev. Cytol. 215, 231-258. doi: 10.1016/S0074-7696(02)15011-X

Toledo-Rodriguez, M., Gupta, M., Wang, Y., Wu, C. Z., and Markram, H. (2003). "Neocortex: basic neuron types," in The Handbook of Brain Theory and Neural Networks, ed M. A. Arbib (Cambridge, MA: MIT Press), 719-725.

Wang, X.-J., and Buzsáki, G. (1996). Gamma oscillation by synaptic inhibition in a hippocampal interneuronal network model. J. Neurosci. 16, 6402-6413.

White, E. L. (1989). Cortical Circuits. Synaptic Organization of the Cerebral Cortex. Boston: Birkhauser. doi: 10.1007/978-1-4684-8721-3

Conflict of Interest Statement: The authors declare that the research was conducted in the absence of any commercial or financial relationships that could be construed as a potential conflict of interest.

Received: 13 December 2013; accepted: 22 March 2014; published online: 08 April 2014.

Citation: Moujahid A, D'Anjou A and Graña M (2014) Energy demands of diverse spiking cells from the neocortex, hippocampus, and thalamus. Front. Comput. Neurosci. 8:41. doi: 10.3389/fncom.2014.00041

This article was submitted to the journal Frontiers in Computational Neuroscience. Copyright (C) 2014 Moujahid, D'Anjou and Graña. This is an open-access article distributed under the terms of the Creative Commons Attribution License (CC BY). The use, distribution or reproduction in other forums is permitted, provided the original author(s) or licensor are credited and that the original publication in this journal is cited, in accordance with accepted academic practice. No use, distribution or reproduction is permitted which does not comply with these terms. 